\title{
Applying Project-Based Teaching Method in Electronic Circuit Course
}

\author{
Yanrong Ouyang ${ }^{\text {a }}$, Tao Zhang \\ Wuhan Mechanical College, Wuhan, 430075, China \\ ayanrong_ou@163.com
}

\begin{abstract}
Circuit course is an important basic courses, with a large of theory and practice contents. This paper discussed the background of electronic circuit course teaching reform, the basic requirements of the project and implementation of application, and a case applied project-based teaching method is shown.
\end{abstract}

Keywords: teaching method; electronic circuit; vocational education.

\section{Introduction}

Circuit course is an important basic course, with a large of theory and practice contents. For a student who just contacts electrical knowledge, he is with few basic knowledge, and lack of theory learning ability. Project-based teaching method is a flexible open and broad teaching approach, cultivates students professional ability, application skills and social skills, reflecting the subject role of students, improving courses quality greatly.

\section{The Premise of Project-based Teaching Method}

Under the theory of constructivism, "stories", "cooperation", "communication" and "construction" are four basic elements in the learning environment of project teaching method. Teaching situations in the environment must be conducive for students to construct learning content. Cooperation should conduct through the whole process of learning activities. Between teacher and students, or students and students, it's important of learning from the data collection and analysis, the study of self-feedback and learning outcomes evaluation and the final construction of meaning. Communication is an integral part of the cooperation process. The members of the Panel exchange ideas and discuss how to accomplish its mandated tasks. In addition, the cooperative learning process is the communication process. In the process, each learner's thought is shared to the entire learning community. Meaning construction is the ultimate goal of teaching process. Its meaning refers to the law of nature, as well as the internal relations of things. students constructing meaning is helpful for participants to understand the contents of the current study reflecting the nature of things, the law, as well as the intrinsic link between it and other things.

Project-based teaching is a teaching mode based on theory of constructivism essentially, which stresses that participants are organized to keep communication with the peer teaching method, in the form of cooperative learning groups in certain situations. Meanwhile, project-based teaching method is based on the real life to solve real-life problems, organizing participants to solve problems continually and completing the meaning construction of knowledge.

Here, the project is a task with concrete, practical application value. It should meet the following conditions:

The working procedure is used to learn certain teaching content, with certain value of application.

A teaching topic can be combination of theoretical knowledge and practical skills.

It is related with the real process or real-life activities directly.

Trainees have opportunities for independent planning and implementation, within a certain time to organize and arrange their own learning behavior.

It has clear and concrete results for demonstration.

Students themselves overcome and deal with difficulties and problems arising in the work of the project. 
Project has a certain degree of difficulty, new knowledge and skills are used by learners to solve the practical new problems.

At the end of the project, project results are evaluated by teachers and students together.

In project-based teaching, learning process is a kind of practice by all the involved roles, the process of projects is more important than the final result.

In project-based teaching, students understand and grasp the knowledge and skills demanded by the course, experience the hardships and joys of innovation, train ideas and methods to analyze and solve problems.

The general teaching structure of project-based teaching is shown in Figure 1.

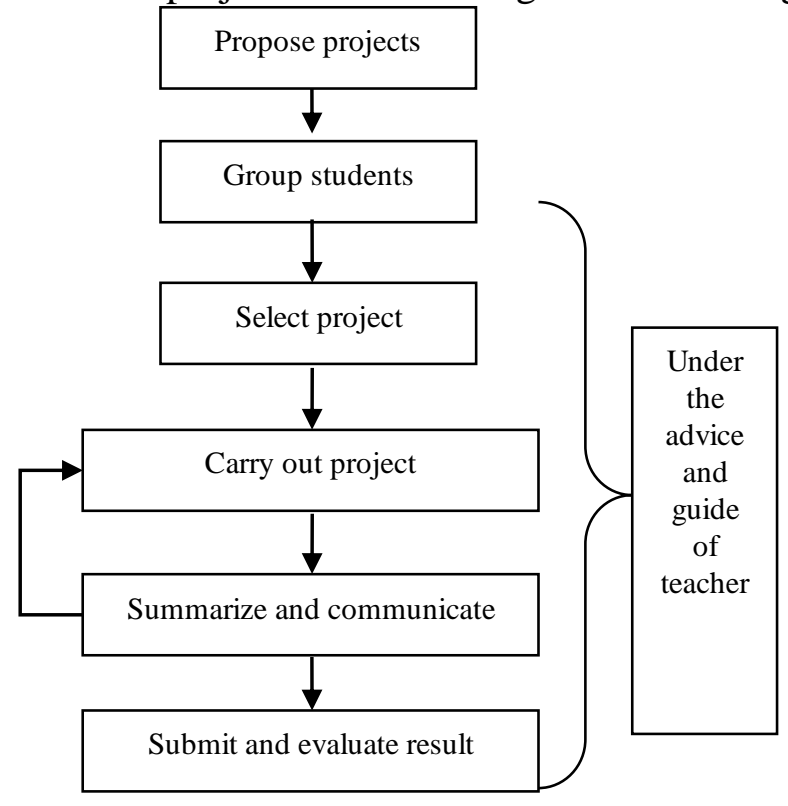

Fig.1 general teaching structure

\section{Implementation process of project-based teaching method}

\subsection{Designing project}

In electronic circuit course, the in order to design the mode of project-based teaching, It is necessary to start from the innovative teaching methods, carrying out the reconstruction of the classroom, doing a good job of curriculum integration, applying the method of multiple evaluation methods to the teaching quality management, and realizing the training objectives based on the practical ability.

Constructive teaching emphasizes activity oriented classroom activities, and activities are the carrier of classroom's teaching. The teacher designs "activities" for students before the teaching to help students participating in the process of activities. Through discussion, communication, exploration, researching and practicing, students' thinking are stimulated and students interests in learning are improved. At the same time, students are trained for inquiry learning.

To work as a starting point to stimulate students' interest in learning, it's important to cultivate students ability of maintenance and accumulate of practical experience, with particular emphasis on the teaching of creating teaching situations where students study with happiness. To reflect the integration, modern means, and multimedia projection diagram are fully used. Project teaching needs to innovative teaching methods to change the status quo of passive learning and to focus teaching activities from the teacher's "teaching" into the students' learning".

The innovation of project teaching in the teaching method pays attention to students' experiences in the process of complete project. Students combine life experience and new knowledge when participating in the learning activities, and enrich their knowledge in the completion to stimulate students' interest in learning. 
In order to meet the requirements of training students, in electronic circuit course, we reconstructed the teaching contents, break the traditional chapter structure, and put the knowledge and skills into practice. Through the specific manufacture task or experiments to enable students to understand the composition of the electronic circuit, simple principle and application, so as to cultivate students' ability to apply electronic circuit. At the same time, debugging and maintenance in the process of the production of specific tasks can improve the students' ability to repair and debug electronic circuits, and then lay a good foundation for professional maintenance.

\subsection{Application process}

Electronic circuit course takes the project as the center combined with the characteristics of the course itself. Each project is driven by specific tasks in accordance with the order of "task analysis", "task realization", "project evaluation". The implementation process is shown in the following.

Determine learning goals

teach academic knowledge

design project

Prepare laboratory

Implement project

Submit project results

Evaluate project results

The teaching methods and means have been reformed. Students are the main body, highlighting the visual image. In addition to the traditional lecture-style teaching method, the teaching method includes problem teaching, discussion teaching, physical teaching and autonomous learning.

\subsection{Course assessment}

Curriculum assessment is a key part of the assessment to reflect the following five aspects.

Demonstration put emphasis on the assessment of students' ability to complete the circuit board.

Process means the evaluation of students learning attitude, learning methods, operational skills comprehensively which are reflected by the influence of teaching on the formation of students' ability.

Written test.

Group mutual evaluation.

Teachers' evaluation of the project team.

The curriculum evaluation system is core of ability evaluation. In the final performance evaluation, the results of the final exam and 5 training projects accounted for $40 \%$, the overall design results accounted for $20 \%$.

\section{Analysis on teaching effect}

In the teaching practice, we have made use of project-based teaching model of basic theory, basic professional skills teaching. Before the reform, student mainly practiced circuit based on experiment box. After the reform, the students set up their own welding circuit. The students understood every device, each connection between the pins. Trainees who successfully completed the overall rate of welding circuit are $95 \%, 30 \%$ has reached the professional level in terms of layout, cable and solder. In General, instructors and trainees feel better, and students are willing to participate in this study.

\subsection{Promoting students study habits}

Applied project-based teaching method, most participants participated the learning by asking questions in class and doing homework with high quality. For group and individual honor, students look up references from library and websites. They preview more and try more experiments. They discuss and review with more frequency. With project-based teaching model, students are under the guidance of faculty and used to put new knowledge into practice. They can think on the problems in practice rationally, consolidate new knowledge in practice, so as to form a good habit of previewing and reviewing. 


\subsection{Increase the love of learning}

The attention of participants concern on the process of project-based teaching, teacher is the organizer in classroom. The students are the core of classroom. Throughout the process of teaching, presentations, displays, hands-on workings are finished by students alternately. A student must always pay attention to keep up with teaching, in small group discussions and exercises, students cannot wander and do other things. This method can produce a strong warm classroom atmosphere.

\subsection{Training a wide range of capacities}

In project-based teaching model, school discipline and efficiency are improved, students are cultivated a wide range of capacities. Such as the participant's professional competence, social competence, ability, character conversion, and so on. Students are enabling to learn to analyze problems and problem-solving skills. through the teaching methods of teaching, students develop the cultivation of social ability, personal honor and the group honor, and then foster students ' sense of participation and team spirit.

\section{Conclusion}

Project-based teaching method is still in the exploration phase. Though we have been widely used in teaching practice and achieved some good results, every educator should continue learning, practice and research it. The advantages of this method should be developed in practice.

\section{References}

[1] Feng Yunying,Project teaching computer network technology optimization course, Theoretical Horizon, Vol.18(2016), p.115-116.

[2] Niu Yan'e Li Ning, Research and practice of project-based teaching methods for "hydraulic and pneumatic technology", Machine Design and Manufacturing Engineering, Vol.45(2016), p.92-94.

[3] Jiang Shuling, Wang Hongbo, Exploration on the Application of Project-based Teaching Approach to Higher Vocational "Basic Accounting" Course, The Science Education Article Cultures, Vol.19(2016), p.94-95.

[4] Ma Jinwei,Zhang Fuqun, Research on the Implementation of Project Teaching Method in the Course of Computer Teaching, Journal of Hubei Correspondence University, Vol.29(2016), p.110-111. 